\title{
Meslek Yüksekokulu Öğrencilerinin Nomofobi Düzeyleri Üzerinde Bir Araștırma
}

\author{
Murat Burucuoğlu*
}

Ondokuz Mayıs Üniversitesi İktisadi ve İdari Bilimler Fakültesi, Samsun.

\section{Öz}

İletişim ve bilgi teknolojilerinde yaşanan gelişmelerle birlikte bireylerin mobil cihaz ve akıllı cep telefonu kullanımlarında değişimler yaşanmıştır. Yaşanan gelişmeler akıllı cep telefonlarmın bireylerin hayatında önemli bir yer edinmesine neden olmuştur. Akıllı cep telefonları bireylerin hayatın kolaylaştırıcı birçok fayda sunduğ gibi aşırı kullanımları bazı problemlere neden olabilmektedir. Bu problemlerden birisi de nomofobi'dir. Bu araştırmanın amacı, meslek yüksekokulu öğrencilerin nomofobi düzeylerini belirlemektir. Araştırmada 228 öğrenciye anket yöntemiyle ulaşılarak veriler toplanmıştır. Elde edilen veriler analizinde ortalamalar, $t$ testi ve ölçeğin geçerliliğinin test edilmesinde de doğrulayıcı faktör analizi gerçekleştirilmiştir. Araştırma sonuçlarma göre önlisans öğrencilerinin nomofobi düzeyleri ortalamanın üzerindedir. Araștırma sonucunda kadın ve erkek bireyler arasında nomofobi düzeyleri açısından anlaml farklılıklar bulunmaktadır. Doğrulayıcı faktör analizi sonuçlarına göre de ölçeğin yapısal geçerliliği sağladığı sonucuna ulaşılmıştır. Ölçeğin güvenirliliği Cronbach Alpha katsayısı ile değerlendirilmiştir. Nomofobi ölçeğinin güvenirlilik katsayısı bu çalışmada 0.935 olarak bulunmuştur ve ölçek yüksek güvenilirliğe sahiptir.

Anahtar Kelimeler: Nomofobi, Akıllı Telefon, Meslek Yüksekokulu Öğrencileri

\section{A Research on Nomophobia Levels of Vocational College Students}

\begin{abstract}
Developing communication and information technologies have changed the use of mobile devices and smart phones. Smart phones have become an important part of individuals' lives. Smartphones offer many benefits that will make life easier for individuals but overuse can cause some problems. One of these problems is nomophobia. This study aims to explore the nomophobia levels of vocational college students. The data had been collected through survey. It had been reached 228 students in total. In this study, data were analsed using averages, independent $t$-test and confirmatory factor analysis for scale validity. The study results shown that students' nomophobia scores are above the scale average. According to the results of the research, the nomophobia averages of women and men are statistically different. The confirmatory factor analysis result shown that the scale provides structural validity. Cronbach's Alpha coefficient had beed used in assessing the reliability of the scale. In this study, Nomophobia scale reliability is found 0.935 and the scale has high reliability.
\end{abstract}

Keywords: Nomophobia, Smart Phones, Vocational College Students

\section{Gíriş}

İnternet, iletişim ve bilgi teknolojilerinde yaşanan değişimler cep telefonlarını günümüzde bireylerin hayatlarının önemli bir parçası haline getirmiştir. Günümüzde hem gelişmiş ülkelerde hem de gelişmekte olan ülkelerde cep telefonu kullanımı, özellikle de akıllı cep telefonu kullanımı giderek yaygınlaşmaktadır (Liu vd., 2017: 108). TÜİK tarafından yapılan Hanehalkı Bilişim Teknolojileri Kullanım Araştırmasına 
göre Türkiye'de hanelerin \%96.9'unda cep telefonu veya akıllı telefon bulunmaktadır (TÜİK, 2016). Cep telefonları günümüzde bireyler tarafından arama ve mesajlaşma için kullanılmakla birlikte navigasyon, oyun oynama, sosyal ağlara bağlanmaya kadar çok farklı fonksiyonları için kullanılabilmektedir (Salehan ve Negahban, 2013: 2632).

Özelikle de genç nüfusun yeni teknolojilere uyumu ve mobil cihazları kullanma oranı daha yaşlı olan bireylere göre daha yüksektir (Adnan ve Gezgin, 2016: 144). Genç yetişkinler için cep telefonları sosyal iletişim sıklığını arttırma, ilişkileri geliştirme ve yeni arkadaşlar edinme gibi birçok fayda sunmaktadır (Chen vd., 2016: 856). Diğer taraftan da gençler için kullanışlı olan cep telefonlarının fazla kullanımı fiziksel ve psikolojik problemlere neden olmaktadır (Tamura vd., 2017: 1). Örneğin cep telefonunun aşırı kullanımı, parmaklara zarar vermekte (Ming, Pietikainen ve Hanninen, 2006), uyku problemlerine neden olabilmekte (Tamura vd., 2017) aynı zamanda depresyon (Augner ve Hacker, 2012) gibi psikolojik sorunlara yol açabilmektedir.

Cep telefonu veya akıllı cep telefonunun aşırı kullanımının olumsuz sonuçlarından birisi de nomofobi' dir. Bu çalışmada, teknolojiye kolay uyum sağlayan ve yoğun bir cep telefonu kullanım oranına sahip genç bireylerin nomofobi düzeylerinin araştırılması amaçlanmaktadır.

\section{NOMOFOBİ KAVRAMI}

Akıllı telefonlarla ilgili yaşanan problemlerden biri nomofobi'dir. (Yıldırım ve Correia, 2015: 131). Nomofobi, psikolojik terminolojide mobil teknolojilerin aşırı ve problemli kullanımlarına işaret eden yeni bir kavramdır (Gezgin vd., 2017: 87). Nomofobi bağımlılık problemlerine yakın bir kavram olmakla birlikte fobiler (korkular) arasında yer almaktadır. Nomofobi, yersiz korkular ve bu korkuların yaratmış olduğu olumsuz fiziksel ve zihinsel durumlarla ilişkilidir (Erdem vd., 2016: 924). Modern çağın yeni fobisi olarak tanımlanan nomofobi, bireyin mobil cihaza erişemediği veya cep telefonu üzerinde iletişim kuramadığında yaşanılan korku olarak tanımlanmaktadır (King vd., 2013: 141; Yıldırım ve Correia, 2015: 131). Nomofobi bireylerde telefonunu unuttuğunda, kapsama alanı dışında kaldığında veya telefonunun şarjının bittiği durumlarda ortaya çıkarak bireyin hayatın akışına odaklanmış bir şekilde devam etmesini olumsuz etkilemektedir (Dixit vd., 2010: 339). Akıllı telefonların internet erişiminin olması, sosyal medya uygulamaları ve birçok uygulamanın kullanılabiliyor olması, hızlı iletişime geçme imkanı tanıması bireylerin akıllı telefonlarla daha fazla meşkul olmalarına ve bu cihazlara erişemediğinde daha fazla endişe duymalarına neden olmaktadır (Yıldırım ve Correia, 2015; Yıldırım vd. 2016). Nomofobik bireylerin özellikleri düzenli olarak cep telefonu kullanma ve birkaç cihaza sahip olma, telefona erişim problemi yaşadığında veya sınırlamalarla karşılaştığında kaygı ve sinirlilik yaşama, düzenli olarak ekrana bakıp arama veya mesaj olup olmadığını kontrol etme, telefonları sürekli açık konumda olması ve uyurken bile akıllı telefonu yanından ayırmama şeklinde ifade edilebilir (Bragazzi ve Puente, 2014: 156-157). 
Cep telefonları öğrenciler tarafından çok amaçlı kullanıldığı için öğrencilerin hayatının merkezinde yer almaktadır (Deshpande, 2015: 244). Literatürde genç bireyler üzerinde birçok çalışma gerçekleştirilmiştir. Kaur ve Sharma (2015) öğrencilerin \%79'unun nomofobi geliştirme riski altında olduklarını, \%74'ünün akıllı telefona sahip olduğunu ve çalışmaya katılan öğrencilerin büyük bir bölümünün gece yatarken bile cep telefonlarını açık konumda bıraktıkları sonucuna ulaşmışlardır. Cheever ve arkadaşları (2014) araştırmalarında cep telefonu ellerinden alınan öğrencilerde zaman ilerledikçe kaygı düzeyinde artış yaşandığı sonucuna ulaşmıştır. Gezgin ve arkadaşları (2017) üniversite öğrencileri üzerinde gerçekleştirdikleri çalışmalarında öğrencilerin nomofobi puanlarının ölçek ortalamasının üzerinde olduğunu, iletişim kaybı ve bilgiye erişememe konusunda katılımcıların endişe duydukları sonucuna ulaşmışlardır. Çalışmada, kadın öğrencilerin erkek öğrencilere göre daha nomofobik olduğu sonucuna da ulaşılmıştır. Erdem ve arkadaşları (2016) üniversite öğrencileri üzerinde gerçekleştirdikleri çalışmalarında katılımcıların yarısından fazlasının nomofobik olduklarını ve kadın katılımcıların erkek katılımcılara göre akıllı telefonlarla daha fazla zaman geçirdikleri sonucuna ulaşmışlardır. Tavolacci ve arkadaşları (2015) çalışmalarında üniversite öğrencilerinden her üç kişiden birinin nomofobik olduğunu ve kadın katılımcıların erkeklere göre daha fazla nomofobi eğiliminde oldukları sonucuna ulaşılmışlardır. Yıldırım ve arkadaşları (2016) araştırmaya katılan üniversite öğrencilerinin \%42.6'sının nomofobik davranışlar sergilediğini ve kadın katılımcıların erkek katılımcılara göre daha nomofobik olma eğilimleri sergilediklerini ifade etmişlerdir. Adnan ve Gezgin (2016) ise çalışmalarında öğrencilerin nomofobi düzeylerinin ortalamanın üzerinde olduğunu ancak demografik özellikler bakımından anlamlı farklılıklar olmadığı sonucuna ulaşmıştır. Literatürde yapılan çalışmalar göz önünde bulundurularak aşağıdaki araştırma soruları ve hipotezler geliştirilmiştir.

A.S.1: Öğrencilerin nomofobi seviyeleri nedir?

H1: Öğrencilerin cinsiyetleri ile nomofobi düzeyleri arasında anlamlı bir farklılık vardir.

\section{YÖNTEM}

\subsection{Araştırmanın Amacı ve Örneklemi}

$\mathrm{Bu}$ araştırmanın amacl, meslek yüksekokulu öğrencilerinin nomofobi düzeylerini araştırmaktadır. Bu araştırmanın örneklemini Ondokuz Mayıs Üniversitesi Alaçam Meslek Yüksekokulu'nda öğrenim gören öğrenciler oluşturmaktadır. Araştırmada kullanılan veriler 2016-2017 Eğitim Öğretim yılı güz yarı yılında toplanmıştır. Kolayda örnekleme yöntemiyle 228 öğrenciye ulaşılmıştır. Katılımcılardan veriler anket tekniği kullanılarak toplanmıştır. Katılımcıların demografik özellikleri incelendiğinde katılımcıların \%45.2'si (103) kadın, 54.8'i (125) erkeklerden oluşmaktadır. Araştırmanın örneklemini, ön lisans düzeyinde eğitime sahip, genç, akıllı telefon veya cep telefonu kullanan katılımcılardan oluşmaktadır. 


\subsection{Veri Toplama Yöntemi ve Verilerin Analizi}

Ölçme aracı olarak Yıldırım ve Correia (2015) tarafından geliştirilen ve Yıldırım ve arkadaşları (2015) tarafından Türkçe'ye uyarlanan Nomofobi Ölçeği (NMP-Q) kullanılmıştır. Ölçek Bilgiye Erişememe, Bağlantıyı Kaybetme, İletişime Geçememe, Rahat Hissedememe olmak üzere dört boyuttan oluşmaktadır (Gezgin, Şahin ve Yıldırım, 2017). Ölçeğin Türkçe'ye çevrilmesinde orijinal eserler ve ulusal literatürde yapılan çalışmalardan yararlanılmıştır (Kaplan Akıllı ve Gezgin, 2016; Erdem, Türen ve Kalkın, 2017). Ölçekte yer alan ifadelere bireylerin katılma derecelerini işaretlemeleri istenmiştir. Derecelendirmede 7'li Likert kullanılmıştır (1: Kesinlikle Katılmıyorum, 7: Kesinlikle Katılıyorum). Verilerin analizinde SPSS 20.0 ve AMOS 20.0 programları kullanılmıştır.

\section{BULGULAR}

Araştırmada kullanılan ölçeğin güvenilirliğini ölçmede Cronbach Alpha Katsayısı (CA) kullanılmıştır. Ölçeğin yapısal geçerliliğini değerlendirmede Doğrulayıcı Faktör Analizi (DFA) gerçekleştirilmiştir. C. Alpha katsayısının 0.70'in üzerinde olması, faktör yüklerinin $0.50^{\prime}$ nin, ideal olanının ise $0.70^{\prime}$ in üzerinde olması beklenmektedir (Hair vd., 2006). DFA'nın değerlendirilmesinde x²/sd, GFI, IFI, CFI, RMSEA uyum iyilikleri kullanılmıştır. $x^{2} / \mathrm{df}$ değerinin $2^{\prime}$ den küçük olması iyi bir uyumu, 2 ile 3 arasında olması kabul edilebilir bir uyumu, RMSEA değerinin $0.05^{\prime}$ ten küçük olması iyi uyumu 0.05 ile 0.08 arasında olması kabul edilebilir bir uyumu ifade etmektedir (Schermelleh-Engel, Moosbrugger ve Müller, 2003: 52). GFI, IFI ve CFI uyum iyiliklerinin $0.90^{\prime}$ ın üzerinde olması beklenmektedir ancak $0.80^{\prime}$ in üzerindeki değerler kabul edilebilir değerler olarak görülebilir (Chow, Snowden ve McConnell, 2001: 407). Bu çalışmada nomofobi ölçeğinin DFA uyum iyiliği değerleri $x^{2} / d f: 2.125$, GFI: 0.879, IFI: 0.942, CFI: 0.942; RMSEA: 0.070 olarak hesaplanmıştır. Uyum iyiliği değerlerinden yalnızca GFI değeri 0.90 'ın altında kalmıştır ancak değerin 0.80 'in üzerinde olması kabul edilebilebileceğini göstermektedir.

Nomofobi ölçeğinin CA değeri 0.935'tir. ölçeğin alt boyutlarının CA değerleri ise Bilgiye Erişememe 0.835, Bă̆lantıyı Kaybetme 0.814, Illetişime Geçememe 0.926, Rahat Hissedememe 0.915 'tir. Ölçeğin içsel tutarlığının yüksek olduğu görülmektedir. Ölçeğin çarpıklık ve basıklık değerleri, literatürde belirlenen sınırlar içerisinde yer aldığından verilerin normal dağıldığı varsayılmaktadır. Aşağıdaki Tablo 1'de nomofobi ölçeğine ilişkin tanımlayıcı istatistikler ve DFA sonuçları yer almaktadır. 
Tablo 1. Nomofobi Ölçeği Tanımlayıcı İstatistikler ve DFA Sonuçları

\begin{tabular}{|c|c|c|c|c|c|c|c|c|c|}
\hline \multicolumn{2}{|c|}{ Değişkenler } & Faktör Yükü̈* & $\bar{X}$ & SS & \multicolumn{2}{|c|}{ Değişkenler } & Faktör Yükü̈ & $\bar{x}$ & SS \\
\hline \multirow{4}{*}{ 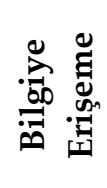 } & NF1 & .842 & 4.26 & 1.962 & \multirow{6}{*}{ 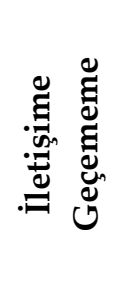 } & NF10 & .690 & 4.51 & 2.040 \\
\hline & NF2 & .890 & 4.40 & 1.911 & & NF11 & .829 & 4.86 & 1.954 \\
\hline & NF3 & .574 & 4.04 & 2.094 & & NF12 & .856 & 4.57 & 1.953 \\
\hline & NF4 & .638 & 4.30 & 1.976 & & NF13 & .920 & 4.66 & 1.972 \\
\hline \multirow{5}{*}{ 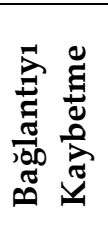 } & NF5 & .650 & 4.20 & 2.189 & & NF14 & .786 & 4.49 & 1.990 \\
\hline & NF6 & .677 & 3.69 & 2.238 & & NF15 & .875 & 4.44 & 2.026 \\
\hline & NF7 & .636 & 4.23 & 2.132 & \multirow{5}{*}{ 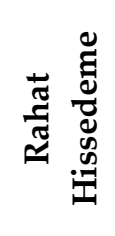 } & NF16 & .760 & 3.25 & 2.008 \\
\hline & NF8 & .649 & 3.32 & 2.131 & & NF17 & .901 & 3.36 & 1.929 \\
\hline & NF9 & .719 & 4.12 & 2.142 & & NF18 & .854 & 3.30 & 1.966 \\
\hline \multirow{2}{*}{\multicolumn{5}{|c|}{ *Standardize Edilmiş Regresyon Katsayısı }} & & NF19 & .759 & 3.19 & 1.941 \\
\hline & & & & & & NF20 & .876 & 3.37 & 2.066 \\
\hline
\end{tabular}

Tablo 1'de görüldüğü üzere ölçekte yer alan ifadelere ilişkin faktör yükleri 0.50'nin üzerindedir. Ölçekte yer alan ifadeler ait oldukları boyutları temsil etmektedir.

Katılımcıların nomofobi düzeyleri ölçekten aldıkları puanlara göre ve aritmetik ortalamaya göre değerledirilmiştir. 7'li likert ile ölçülen ve 20 ifadenin yer aldığ 1 ölçekten alınabilecek minimum puan 20 maksimum puan 140'tır. 0-20 puan aralığ nomofobi yok, 21-60 puan aralığ1 düşük düzeyde nomofobi, 61-100 puan aralığ1 orta düzey nomofobi, 101-140 puan aralığ1 yüksek düzeyde nomofobi olduğunu göstermektedir (Gezgin, Şahin ve Yıldırım, 2017). Katılımcıların aldıkları skorlar değerlendildiğinde 168 (\%73.7) öğrencinin orta ve yüksek yüzeyde nomobiye sahip olduğu 59 (25.9) öğrencinin düşük düzeyde, yalnızca 1 (\%0.4) öğrencide nomofobinin olmadığı sonucuna ulaşılmıştır.

Ölçek ortalamaları değerlendirildiğinde nomofobi ölçeğinden ortalama alınan puan 4.02 , alt boyutlarının ortalamaları ise Bilgiye Erişememe 4.25, Bağlantıyı Kaybetme 3.91, İletişime Geçememe 4.58 ve Rahat Hissedememe 3.29 şeklindedir. Ölçekten alınan puan, ölçek ortalamasının üzerindedir.

Katılımcıların cinsiyetleri ile nomofobi düzeyleri arasında anlamlı bir farklılık olup olmadığına ilişkin bağımsız örneklem t testi sonuçları aşağıdaki Tablo 2'de yer almaktadir.

Tablo 2. Cinsiyete göre Nomofobi Düzeyinin Farklılığına İlişkin Bağımsız t-testi Sonuçları

\begin{tabular}{|l|l|l|l|l|l|l|}
\hline Cinsiyet & $\mathbf{N}$ & $\bar{X}$ & SS & $\mathbf{t}$ & $\mathbf{d f}$ & $\mathbf{p}$ \\
\hline Kadın & 103 & 4.24 & 1.26 & 2.16 & 226 & $0.032^{*}$ \\
\hline Erkek & 125 & 3.85 & 1.41 & & & \\
\hline $\mathbf{p}^{*}<\mathbf{0 . 0 5}$
\end{tabular}

Tablo 2'de görüldüğü üzere kadınlar ile erkekler arasında nomofobi ortalamaları bakımından anlamlı bir fark bulunmaktadır. Kadın katılımcıların nomofobi ortalamaları erkek katılımcılardan yüksektir. 


\section{TARTIŞMA VE SONUÇ}

$\mathrm{Bu}$ araştırmada, önlisans düzeyinde eğitim gören öğrencilerin nomofobi düzeyleri araştırılmıştır. Araştırma sonucuna göre öğrencilerin nomofobi düzeylerinin yüksek olduğu bulgusuna ulaşılmıştır. Bu sonuç üniversite öğrencileri üzerinde yapılan çalışmaların sonuçlarını destekler niteliktedir (Yıldırım vd., 2016; Tavolacci vd., 2015; Gezgin vd., 2017; Adnan ve Gezgin; 2016; Erdem vd. 2016; Erdem, Türen ve Kalkın, 2017). Gerçekleştirilen çalışmalar ve bu araştırmanın sonuçları göstermektedir ki nomofobi gençler arasında giderek yaygınlaşmaktadır (Kaur ve Sharma, 2015). Nomofobi düzeyinin yükselmesi genç bireyleri birçok açıdan olumsuz etkileyecebilecektir. Erdem ve arkadaşları (2017: 10)'nin de çalışmasında ifade ettiği gibi üniversite öğrencilerinin yüksek nomofobi düzeyine sahip olması yakın gelecekte iş hayatına atılacak öğrenciler için iş ortamında birçok probleme neden olabilir. İş görenlerde yaşanacak performans düşüklüğü işletmenin amaçlarına ulaşmasını engelleyecek, nomofobi düzeyi yüksek olan çalışanlarda yaşanacak bilişsel ve dikkat bozuklukları olası iş kazalarına neden olabilecektir.

Araştırmada kadınlarla erkeklerin nomofobi ölçeğinden aldıkları puanların ortalamaları arasında istatistiksel olarak anlamlı farklılıklar bulunmuştur. Kadınlar erkeklere göre daha fazla nomofobi eğilimi göstermektedir. Literatürde birçok çalışmada kadınların erkeklere oranla daha fazla nomofobik olduğu (Yıldırım vd., 2016; Tavolacci vd., 2015; Gezgin vd. 2017; Erdem, Türen ve Kalkın, 2017) sonucuna ulaşılmıştır. Kadınların erkeklere göre daha fazla nomofobik eğilimleri olmasının altında sosyo-kültürel ve psikolojik birçok faktör olabilir. Literatürde kadın ve erkeklerin nomofobi düzeyleri arasında anlamı bir farklılığın olmadığı yönünde de çalışmalar bulunmaktadır (Adnan ve Gezgin, 2016; Dixit vd., 2010). Bu konuda daha detaylı çalışmaların yapılması faydalı olacaktır.

Araştırmanın gerçekleştirildiği örneklem meslek yüksekokulu öğrencilerinden oluşmaktadır. Meslek yüksekokullarının amacı kamu ve özel sektöre ara eleman yetiştirmektir (Ulus, Tuncer ve Sözen, 2015). Ara elemanların kamu ve özel sektörde öncelikli olarak operasyonların gerçekleştirilmesinde yer aldığı düşünüldüğünde nomofobi düzeyi yüksek çalışanların operasyon hataları, performans düşüklüğü, motivasyon eksikliği başta olmak üzere iş kazalarına kadar birçok probleme neden olabileceği öngörülebilir.

Günümüzde iletişim ve bilgi teknolojsinde yaşanan değişimler hızla devam etmektedir. Teknolojide yaşanan değişimlerin gelecekte artarak devam edeceği göz önünde bulundurulduğunda akıllı telefon teknolojsinin gelişiminin de daha ileri

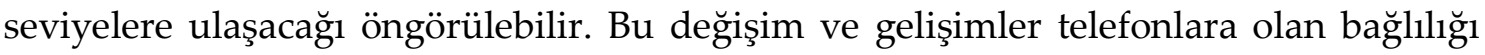
daha üst düzeye çıartabilir. Bu noktada akıllı telefon üreticileri, uygulama ve içerik geliştiricilerin geliştirilen teknolojlerin insan hayatına etkilerini göz önünde bulundurmaları, fiziksel ve ruhsal iyi olma halini olumsuz etkilemeyecek şekilde ürün, hizmet ve içerik üretmeleri bireyler, işletmeler ve toplumun geneli için faydalı olacaktır. 
Araştırma zaman ve maliyet kısıtlarından dolayı sınırlı bir örneklemde gerçekleştirilmiştir. Araştırma sonuçları bu kısıtından dolayı genellenemektedir. Gelecekte araştımacıların iş hayatına yeni başlayan gençlerin nomofobi eğilimleri ile örgütsel davranışları arasındaki ilişkileri inceleyen çalışmalar gerçekleştirmeleri faydalı olacaktır.

\section{KAYNAKÇA}

Adnan, M., \& Gezgin, D. M. (2016). Modern Çağın Yeni Fobisi: Üniversite Öğrencileri Arasında Nomofobi Prevalansı. Ankara Üniversitesi Ĕ̆itim Bilimleri Fakültesi Dergisi, 49 (1), 141158.

Augner, C., \& Hacker, G. W. (2012). Associations between problematic mobile phone use and psychological parameters in young adults. International Journal of Public Health, 57 (2), 437-441.

Bragazzi, N. L. \& Puente, D. G. (2014). A Proposal for Including Nomophobia in the New DsMV. Psychology Research and Behavior Management, 7, 155-160.

Cheever, N. A., Rosen, L. D., Carrier, L. M., \& Chavez, A. (2014). Out of sight is not out of mind: The Impact of Restricting Wireless Mobile Device Use on Anxiety Levels among Low, Moderate and High Users. Computers in Human Behavior, 37, 290-297.

Chen, L., Yan, Z., Tang, W., Yang, F., Xie, X., \& He, J. (2016). Mobile phone addiction levels and negative emotions among Chinese young adults: the mediating role of interpersonal problems. Computers in Human behavior, 55, 856-866.

Chow, J. C. C., Snowden, L. R., \& McConnell, W. (2001). A Confirmatory Factor Analysis of the BASIS-32 in Racial And Ethnic Samples. The Journal of Behavioral Health Services and Research, 28(4), 400-411.

Deshpande, A. (2015). Mobile Addiction and Associated Factors Amongst Youth. Indian Journal of Mental Health, 2(3), 244-248.

Dixit, S., Shukla, H., Bhagwat, A. K., Bindal, A., Goyal, A., Zaidi, A. K., \& Shrivastava, A. (2010). A Study to Evaluate Mobile Phone Dependence Among Students of a Medical College and Associated Hospital of Central India. Indian Jounal of Community Medicine, 35 (2), 339-341.

Erdem, H., Kalkın, G., Türen, U., \& Deniz, M. (2016). Üniversite Öğrencilerinde Mobil Telefon Yoksunluğu Korkusunun (Nomofobi) Akademik Başarıya Etkisi, Süleyman Demirel Üniversitesi İktisadi ve İdari Bilimler Fakültesi Dergisi, 21 (3), 923-936.

Erdem, H., Türen, U., \& Kalkın, G. (2017). Mobil Telefon Yoksunluğu Korkusu (Nomofobi) Yayılımı: Türkiye'den Üniversite Öğrencileri ve Kamu Çalışanları Örneklemi. Bilişim Teknolojileri Dergisi, 10 (1), 1-12.

Gezgin, D. M., Şahin, Y. L., \& Yıldırım, S. (2017). Sosyal A ̆̆ Kullanıcıları Arasında Nomofobi Yaygınlığının Çeşitli Faktörler Açısından İncelenmesi. Eğitim Teknolojisi Kuram ve Uygulama, 7(1), 1-15.

Gezgin, D. M., Şumuer, E., Arslan, O., \& Yıldırım, S. (2017). Nomophobia Prevalence among Pre-service Teachers: A case of Trakya University. Trakya Üniversitesi Eğitim Fakültesi Dergisi, 7(1), 86-95. 
Hair, J. F., Black, W. C., Babin, B. J., Anderson, R. E., \& Tatham, R. L. (2006). Multivariate Data Analysis, (Vol.6.). Upper Saddle River, NJ: Pearson Prentice Hall.

Kaplan Akıllı, G. \& Gezgin, M. D. (2016). Üniversite Öğrencilerinin Nomofobi Düzeyleri ile Farklı Davranış Örüntülerinin Arasındaki İlişkilerin İncelenmesi. Mehmet Akif Ersoy Üniversitesi Ĕ̆itim Fakültesi Dergisi, 40, 51-69.

Kaur, A., \& Sharma, P. (2015). A Descriptive Study to Assess the Risk of Developing Nomophobia among Students of Selected Nursing Colleges Ludhiana, Punjab. International Journal of Psychiatric Nursing, 1 (2), 1-6.

King, A. L. S., Valença, A. M., Silva, A. C. O., Baczynski, T., Carvalho, M. R., \& Nardi, A. E. (2013). Nomophobia: Dependency on Virtual Environments or Social Phobia?. Computers in Human Behavior, 29 (1), 140-144.

Liu, Q. Q., Zhou, Z. K., Yang, X. J., Kong, F. C., Niu, G. F., \& Fan, C. Y. (2017). Mobile Phone Addiction and Sleep Quality Among Chinese Adolescents: A Moderated Mediation Model. Computers in Human Behavior, 72, 108-114.

Ming, Z., Pietikainen, S., \& Hänninen, O. (2006). Excessive Texting in Pathophysiology of First Carpometacarpal Joint Arthritis. Pathophysiology, 13(4), 269-270.

Salehan, M., \& Negahban, A. (2013). Social Networking on Smartphones: When Mobile Phones Become Addictive. Computers in Human Behavior, 29, 2632-2639.

Schermelleh-Engel, K.,Moosbrugger, H., \& Müller, H. (2003). Evaluatingthe Fit of Structural Equation Models: Tests of Significance and Descriptive Goodness of Fit Measures. Methods Of Psychological Research Online, 8(2), 23-74.

Tamura, H., Nishida, T., Tsuji, A., \& Sakakibara, H. (2017). Association between Excessive Use of Mobile Phone and Insomnia and Depression among Japanese Adolescents. International Journal of Environmental Reseach and Public Health, 14, 701.

Tavolacci, M. P., Meyrignac, G., Richard, L., Dechelotte, P., \& Ladner, J. (2015). Problematic Use of Mobile Phone and Nomophobia among French College Students. The European Journal of Public Health, 25 (suppl 3), 206.

TUiK Haber Bülteni (2016), Hanehalkı Bilişim Teknolojileri Araştırması, 03 Mayıs 2017 tarihinde http://www.tuik.gov.tr/PreHaberBultenleri.do?id=21779 adresinden erişildi.

Ulus, L., Tuncer, N., \& Sözen, Ş. (2015). Mesleki Eğitim, Gelişim ve Yeterlilik Açısından Meslek Yüksekokullarının Önemi. Uluslararası Türk Eğitim Bilimleri Dergisi, 3(5) 168-185.

Yıldırım, C., \& Correia, A. P. (2015). Exploring the Dimensions of Nomophobia: Development and Validation of a Self-Reported Questionnaire. Computers in Human Behavior, 49, 130137.

Yıldırım, C., Sumuer, E., Adnan, M., \& Yıldırım, S. (2016). A Growing Fear: Prevalence of Nomophobia Among Turkish College Students. Information Development, 32 (5), 13221331. 